\title{
Learners' use of strategies for effective vocabulary learning
}

J MOIR AND I S P NATION - Victoria University, Wellington

\section{ABSTRACT}

This paper is based on a set of case studies of learners coping with the learning of vocabulary on an intensive English program. Although the learners were all highly motivated, most of them engaged in learning behaviours that they knew were not as beneficial as they could be or which went against what they had learned in class. Ir is argued that the main cause for this was the learners not taking personal responsibility for their learning and relating it to their own long-term goals. It is also suggested that some of this behaviour was encouraged by certain teaching and testing practices.

\section{Introduction}

In recent years, in line with a more learner-focused view of education, there has been increasing interest in language learners themselves, and how they approach the task of learning. This learner-centred focus has had two significant effects on classroom teaching and curriculum planning.

First, in response to the recognition that learners are individuals with unique learning needs, teachers and course designers are aiming to design courses and classroom materials with a specific group of learners in mind. A second effect of learner-centred education is the provision for learners to work more independently, both in and out of the language classroom, allowing learners more control over what is learned, and when and where that learning takes place. This may be realised in a focus on learner strategies.

Although there has certainly been a trend towards a learner-centred focus in whole-class instruction, in many institutions there are still several aspects of learning in a whole-class environment that require learners to engage in activities or tasks that are imposed by the curriculum, and so there are a number of tasklevel decisions that must be made by learners within the classroom context. Since the ability to make strategic decisions about learning at task-level is likely to be a determinant of effective learning, it is important to investigate the strategies that learners use to approach tasks for which some aspects, such as format and assessment, are already predetermined by the curriculum.

Studies of the vocabulary-learning strategies used by second- or foreignlanguage learners have shown that learners differ in the range of strategies they 
use and in the effectiveness with which they apply these (Gu and Johnson 1996; Lawson and Hogben 1996; Schmirt 1997). There is also a large body of both first and second language research which demonstrates the effectiveness of particular strategies (Nation 2001). These include 'simple' strategies like the use of rehearsal, repetition, and instantiation, more complex strategies like word-part analysis, guessing from context clues, and a range of elaborative strategies like the keyword technique. Teachers are now aware of many of these and it is not unusual to see such strategies taught and practised in English proficiency courses and incorporated into course books (Dunmore 1989).

There are now increasingly elaborated and detailed taxonomies of vocabulary learning strategies (Schmitt 1997), but some of these suffer from the lack of an externally validated framework to check on how completely they cover the area. The present study draws on a model of syllabus design in an effort to rectify this omission. A syllabus design framework is chosen principally because the present study focuses on learners' vocabulary-learning strategy use in the context of an English proficiency course. The vocabulary component of this course can be viewed as a piece of syllabus design and learners' beliefs and behaviour can be examined using the main parts of the syllabus design process as a guide, namely goals, choice of content, format and presentation, and monitoring and evaluation of the learning (Nation 2000; Murdoch 1989). When we place vocabulary strategy taxonomies against such a framework, we find that almost all the strategies focus on format and presentation, that is strategies for understanding and remembering vocabulary. Schmitt (1997) calls these discovery and consolidation strategies. With the small exception of $\mathrm{Gu}$ and Johnson's (1996) metacognitive regulation category where knowing which words are important to learn is mentioned, most taxonomies do not consider goalsetting and vocabulary-selection strategies, and strategies for evaluating and monitoring progress in vocabulary learning.

\section{Vocabulary learning goals}

The goals of a vocabulary learning program should include:

1 the learning of useful vocabulary which relates to the learners' language learning goals such as learning English for academic study, for social uses, or for particular purposes such as reading newspapers or watching TV;

2 retaining the learning so that the vocabulary knowledge is still available after the course ends, and

3 making the vocabulary available for meaning-focused use both receptively and productively.
To reach the first goal learners need to apply the strategy of appropriate choice, that is, choosing the most useful words to learn, and the strategy of appropriate focus, that is, deciding what to learn about them. These are both very important strategies because words differ considerably in their frequency and distribution (Nation 2001: Chapter 1) and there are many aspects of knowledge involved in knowing a word (Richards 1976; Schmitt 2000).

To reach the second goal, long-term retention of the vocabulary, it is necessary to use strategies that encourage deep processing of the vocabulary, for example, Schmitt's (1997) memory strategies and cognitive strategies. Learners also need to ensure that there is spaced repetition and review which relate to Schmitt's metacognitive strategies.

To reach the third goal, making vocabulary available for use, learners need to seek opportunities to use their learning.

\section{The study}

The study sought to answer the following questions.

What beliefs and strategies do learners draw on to guide their vocabulary learning?

In what ways are these beliefs and strategies affected by the learners' purposes in learning English, the nature of the course, and the learners' previous experience?

How effective are these strategies?

This study differs from other strategy studies in that it uses a broader, curriculum-based view of strategies and uses interviews rather than surveys (Gu and Johnson 1996; Schmitt 1997;) and 'think-aloud' tasks (Lawson and Hogben 1996) to gather data. Like Lawson and Hogben's study, the present study involves a measure of vocabulary learning.

The study examines the vocabulary-learning strategies of ten adult language learners in an intensive ESL course. The informants were interviewed in the hope of shedding some light on the learners' strategy use and their beliefs about learning. All were studying on an English proficiency program, a full-time, twelve-week intensive course focusing for the most part on academic English. Many of the international students in the course hope to use a pass mark on the course as proof of sufficient English proficiency to enter university and are highly motivated.

The vocabulary program followed by the informants interviewed in this study was designed to increase learner awareness of what is involved in vocabulary learning, and to improve productive vocabulary. The program requires 
learners to study between 30 and 40 words of their own choosing each week, using a vocabulary notebook issued to all learners at the beginning of the course. Schmitt and Schmitt (1995) describe the principles and advantages behind using a vocabulary notebook. The vocabulary notebook has columns to complete for each word, requiring information relating to pronunciation, meaning, grammatical use, collocations, a sentence containing the target word, and other items from the same word family. Progress in vocabulary learning is monitored through a weekly test, in which learners are required to demonstrate their knowledge of the words they have chosen to study. At the beginning of the program, students are given instruction in a number of vocabulary-learning strategies, such as the key-word technique and the use of word cards. Learners are also provided with information on how to choose vocabulary to study, and what is involved in knowing a word.

The weekly test that learners prepared for was conducted in the following way. Each learner gave a list of the words they had studied to the teacher. The teacher then wrote an abbreviation next to some of the words indicating what the learner had to do. $\mathrm{C}$ meant the learner had to write some collocations for the word, $S$ meant that the learner had to write a sentence using the word,

$P$ indicated that the learner had to break it into parts, and so on. In this way each learner sat their own personalised test.

It is believed that allowing learners to select their own vocabulary to study would be beneficial in two ways. First, self-selecting vocabulary allows individual learners to focus on vocabulary that meets their own needs and, second, it is believed that selecting their own words would result in increased motivation to learn.

Data for this study was taken from semi-structured interviews conducted with ten adult students. The interviews elicited information relating to the learners' current vocabulary learning behaviour within the ESL program, and beliefs about vocabulary learning. A short vocabulary test was also devised to measure the informants' knowledge of words learned in the vocabulary program three weeks prior to the interview. Most of the informants for this study had a receptive vocabulary of between 3000 and 5000 words, as measured by Nation's Vocabulary Levels Test (1990) at the beginning of the program. Table 1 provides a brief profile of the students, who have all been assigned pseudonyms.

Informed consent was obtained from all ten informants, and each was provided with an information sheet explaining the nature of the research and their expected role should they decide to participate in the project. They were also given the opportunity to discuss the project with the researcher before dita were collected.
Table I:The learners involved in the study

\begin{tabular}{llllll}
\hline Informant & $\begin{array}{l}\text { Country of } \\
\text { origin }\end{array}$ & \multicolumn{1}{l}{ Agelgender } & $\begin{array}{l}\text { Total years } \\
\text { studying English }\end{array}$ & $\begin{array}{l}\text { Years in English- } \\
\text { speaking country }\end{array}$ \\
\hline Mohamed & Bangladesh & 32 & M & 14.0 & 0.7 \\
Masa & Japan & 23 & M & 5.0 & 1.7 \\
Natalie & Hong Kong & 24 & $\mathrm{~F}$ & 11.0 & 0.3 \\
Haruko & Japan & 32 & $\mathrm{~F}$ & 6.0 & 2.0 \\
Kate & China & 27 & $\mathrm{~F}$ & 7.0 & 0.3 \\
Sandy & Korea & 27 & $\mathrm{~F}$ & 7.0 & 0.3 \\
Abdi & Somalia & 23 & $\mathrm{M}$ & 4.0 & 0.4 \\
Jack & Korea & 20 & $\mathrm{M}$ & 6.0 & 0.8 \\
Debbie & Sri Lanka & 24 & $\mathrm{~F}$ & 2.0 & 0.3 \\
Sun ae & Korea & 22 & $\mathrm{~F}$ & 6.0 & 0.4
\end{tabular}

\section{Interview design}

The interview schedule was designed primarily to elicit information relating to the informants' current vocabulary-learning behaviour and their beliefs about vocabulary learning, and was divided into three parts.

\section{VOCABULARY LEARNING WITHINTHE PROGRAM}

The first part of the interview schedule was intended to elicit information from each of the informants relating to their approach to learning vocabulary within the context of the program. Although all informants were restricted to a certain extent by the confines of the vocabulary-learning program, consisting of a learning notebook and weekly test, it was believed that learners would have their own approach to the learning task, adjusted to some extent according to their own needs. Questions in this section of the interview schedule related to strategies of personal goal-setting, selection and grading of content, methods and techniques, monitoring and evaluation. It was hoped that responses to these questions would reveal the degree of learners' willingness to make decisions relating to each of these aspects of learning vocabulary in a way that promoted their learning.

\section{OTHER VOCABULARY LEARNING}

The next part of the interview related to informants' vocabulary learning ourside the course. It was believed that most informants would have some sort of system for learning vocabulary for their own use. Informants were asked to consider any direct attempts to learn new vocabulary and to describe any strategies or techniques they employed. This section of the interview also encouraged informants to consider the relationship between their strategies for vocabulary 
learning and the systematic approach to vocabulary learning used in the course. In the second part of this section, informants were asked about their experience of learning vocabulary in past language courses, in their home country, in New Zealand, and in other countries. It was hoped that knowledge of informants' past vocabulary-learning experience might provide some insight into current beliefs and behaviour.

\section{BELIEFS ABOUT VOCABULARY LEARNING}

The third section of the interview schedule related to the informants' personal beliefs about learning vocabulary in a second language. To some extent, most informants had already expressed their beliefs about vocabulary learning in comments made in previous parts of the interview, but this section gave informants the opportunity to expand on ideas and to reflect on their beliefs.

\section{Test design}

In order to test informants' retention of knowledge of words studied during the program, a short test was devised. Due to the nature of the vocabulary-learning task set for the program, it was expected that informants would show a reasonable depth of knowledge of the items chosen for the test. The test thus focused on depth of knowledge of a few words, rather than breadth of knowledge - how many words were known (Sokmen 1997; Wesche and Paribakht 1996).

An interview test designed to assess the informants' depth of knowledge of the target items, and their ability to use these words productively was therefore chosen as the most appropriate measure of the informants' retention of vocabulary items. For each informant, ten words were selected at random from a list of words studied by that informant three weeks prior to the interview. Informants were presented with the list of words based on their individual lists, and were asked to give as much information as possible about each word, even if uncertain of its meaning or usage. The researcher probed the informants' knowledge of each item. However, informants were not pressured to provide answers quickly, but were allowed time for reflection and recall. In those cases where informants were completely unable to recognise the word in isolation, sample sentences were provided to prompt recall. As much as possible, sentences were creared that gave sufficient context to aid recall of word knowledge, but not enough to allow informants to guess meaning. In some cases informants did attempt to guess the meanings of items presented in context, and where it was obvious that the informants were guessing from context rather than recalling meaning, these answers were not included in the grading of the tests. Each learner thus met the researcher twice-once for the vocabulary interview test and then three weeks later for the vocabulary-learning beliefs and strategies interview. Let us now look at the findings of the second interview.

\section{Analysing the strategy interviews}

It must be acknowledged that any methodology requiring students to describe their own learning behaviour is open to charges of unreliability. It is also necessary to consider the possibility that informants are either not sufficiently aware of their own behaviour to offer an accurate description, or have a tendency to direct their responses towards a perceived researcher expectation. One or two of the informants in this study certainly demonstrated a tendency to describe their teachers' instructions rather than their own learning behaviour. However, wherever possible, the researcher deflected such responses and encouraged informants to think more carefully about their actual behaviour and personal beliefs, as is shown in the example below taken from Haruko's interview.

$\mathrm{H}$ : At the beginning of the course J taught us about how to do that. She said we should ...

R: OK, that's what J said you should do, can you tell me what you actually do?

$\mathrm{H}$ : (laughs) ... actually usually I don't do that ...

Student responses describing learning behaviour were also supported by examples from recent vocabulary tests and notebook work in order to increase the reliability of the self-report data.

Analysis of the interview transcripts revealed that most of the informants were not using a range of vocabulary-learning strategies that would shape the program to fit their own needs. Moreover, vocabulary scores from the tests conducted with these informants also revealed limited long-term retention of meaning and ability to use items learned for the vocabulary component of the program.

While most of the interviews revealed a similar pattern of vocabularylearning behaviour, one informant, Abdi, differed significantly in his approach to the task. Abdi demonstrated a high level of responsibility for his own learning, and a strong awareness of aspects of vocabulary and of the vocabularylearning strategies required to complete the task to meet his own needs. For this reason, Abdi's behaviour is discussed separately.

Before continuing with a description of how the learners approached the task, it is important to stress that the learners spent a considerable amount of time studying vocabulary for the program. Although the amount of time varied from week to week, most informants believed they spent between five and six hours, and two informants, Haruko and Sandy, reported spending up to eight or nine hours per week on this task. Interestingly, Abdi, the learner who was approaching the task most effectively, reported spending slightly less time on the task than the other learners, approximately four hours per week.

It is clear that these learners were investing a substantial amount of time in this vocabulary development program. It is therefore important to find out 
how these learners approached the task, and how effective their learning really was.

\section{Nine learners' approaches to vocabulary learning}

Let us look at the strategies the learners used following the syllabus-design components of content, presentation and evaluation.

\section{SELECTION OFWORDS}

The aspect of vocabulary learning in which the informants appeared to demonstrate the least ability to personalise was in the selection of words to be learned each week, and they often selected words that were of limited use or little personal interest. Although some words were selected from a wider range of sources, such as newspapers, personal reading, television or radio, most of the informants selected vocabulary from texts presented in class, and focused on academic or 'difficult' words.

For many of the informants, the process of selecting words to study was quite random.

I don't know this word - I don't know meaning - so I don't know useful or not.

I just choose some words I don't know before. This is very popular way for us.

Although, in rare cases, informants selected words because of particular personal interest, most of the words chosen by the informants in this study were selected purely because they were unknown.

Most informants also appeared to place little value on the selection of words to learn, selecting words quickly in order to allow time for finding out information about them and memorising them for the weekly test.

I don't have no time to finding the words. Just I open my book and then I just pick up the words.

For the most part, words selected by the informants were of low frequency and/or limited distribution, and informants themselves often believed the words chosen to be of limited use to them personally, as is illustrated in this comment from Haruko.

I choose very big academic word, but academic word is not useful. Of course I

should know that word, but I think I don't use after this course.

\section{ASPECTS OFWORD KNOWLEDGE}

To a certain extent, information about items to be learned is largely predetermined by the vocabulary workbook with which each student in this program is expected to work. The need to find such information for each target item is further reinforced by the format of the weekly test.

Almost all informants showed a preoccupation with meaning, often at the expense of other crucial aspects of word knowledge, and many of the informants believed that a first language translation of items to be learned was sufficient to enable effective use of words. Several expressed their lack of interest in depth of word knowledge, stating that aspects of word knowledge such as collocations and other words in the same word family were only learned to fulfil course requirements.

I need meaning, and then I must fill ir (vocabulary-learning notebook $-R$ ) with everything. I find everything - collocarions and noun, adjective or something, and then family word. Actually, I don't need that, bur I have to do because of the test. If I find a word by myself, just meaning is O.K. for me.

In Korea I never tried like that, bur here they demand me to memorise collocation for that test. I think ir's not useful to me. I'm not used to use collocation.

Just meaning is important for me. Collocation and word family thing not so important, because I'm not English-speaking people.

This dismissal of word knowledge other than meaning was clearly arriculated in many of the interviews, demonstrating a general lack of awareness as to how depth of vocabulary knowledge might contribute to ability to use the items both productively and receptively. The informants also often failed to make a connection between depth of word knowledge and their inability to use items communicatively, as is shown in these two consecutive comments made by Jack in his interview.

I don't think those things (grammatical information, collocation er cetera $-\mathrm{R}$ ) is imporrant for me now. Mostly 1 just find Korea meaning, this is best way for me.

Actually, most serious problem for me - I don't know how to use that word. I know meaning, but I can't use that one. I don't know why.

The informants were also asked to provide a sentence using each target word for the weekly test. Here again, the majority of the informants demonstrated an unwillingness to adapt the learning to their own goals by creating their own sentences. In most cases, sentences were copied from examples provided in language-learning dictionaries. Often, sentences were copied exactly, or shortened slightly to make them easier to remember. 
I have to find a sentence because of test. I copy exactly because that is a perfect sentence. If I change it ... usually it's a wrong sentence.

Usually (I) get sentence from the dictionary. I think dictionary is useful for me, and I can trust the dictionary.

This approach to learning the target words seemed to have a negative effect on some informants' ability to use the items communicatively. For example, in the case of one of her tested words, Sandy was unable to provide an example of an item in use, because she could not remember the sample sentence she had memorised for the test. By copying a 'perfect' sentence from the dictionary, she had limited her own expectations of her ability to use new vocabulary. Sandy seemed utterly aghast at the thought of creating new sentences containing the target word, even when she had demonstrated a reasonable level of understanding of the word.

\section{LEARNING AND MEMORISING WORDS}

\section{Strategies}

Rote learning or 'memorising' was the most common consolidation strategy used by nine of the ten informants interviewed for this study. All informants spent a considerable amount of time reading over the information recorded in vocabulary learning notebooks, or copying it out several times into larger notebooks. Three of the nine informants also self-tested vocabulary, by covering second-language translations or definitions while reading through the list.

Although all students had been instructed on the use of various strategies for learning vocabulary at the beginning of the program, most of those interviewed had veered away from using these new strategies, preferring to rely on the tried and tested strategy of rote learning. In some cases, the informants had valid arguments for avoiding the use of new vocabulary learning strategies, as is shown in the comments of these two learners discussing the key-word technique.

Someone said, you know, find a similar word in my own language, same sound, to help remember, and I tried do that. After that, consequently my English pronunciation become very strange. I don't know, maybe ir depend on the people, the student, bur ... in my case it make harmful effect for me. I won't do that any more.

I think it's good technique for deeply remember, but for this test I have limited time. To make good collocation word, to find good picture is take time. If particular I want to remember special words, maybe I would like to try this idea, but not often ... takes a long time.

Haruko
It is clear from these comments that these learners have at least considered strategies other than memorising to help them learn the words each week, but have decided not to use them.

\section{A limited time frame}

One recurrent theme when discussing learning the items chosen for vocabulary development was the idea that the words were only learned in the short term. Many references were made to time constraints in relation to the test, and in one case it was explicitly stated that it was only necessary to remember the words for a short time.

I just memorise that list, reading and writing. It's easy - we have to remember that for just one day.

While this example is perhaps a little extreme and not representative of the whole group, learning behaviour such as 'cramming' on the morning of the weekly test indicates that many of these informants were concerned mostly about remembering the words for the test, rather than as a long-term goal. This is further demonstrated by the general failure to revise items after the test.

\section{REVISION OFWORDS}

Of the nine informants, not one regularly revised words learned in previous weeks, although some recognised the importance of revision and believed lack of it to be contributing to their inability to commit new words to long-term memory. The most common reason cited for failure to revise items was lack of time. Informants were busy with other aspects of the program and vocabulary revision became less of a priority.

After the test I am trying to remember and use these words, as because if I don't use this word I can't remember and the word become rusty. But after finishing the test ... each week there is homework for learning next 30 words. I don't get time to look at this previous learning words.

Some of the informants believed that teachers should allocate class time to revision of vocabulary, and to follow up vocabulary development by requiring learners to use the new words in writing or speaking.

\section{SELF-EVALUATION AND MONITORING}

Many of the learners believed that they were not learning vocabulary effectively in this part of the program. It was believed that many of the words had been forgotten, and that they had limited ability to use those words communicatively. 
This perception was shown to be true in the results of the tests. Many of the informants attributed their low retention of vocabulary they had studied to the actual words they selected. Several commented that the words were nor useful or relevant to their own lives. Others complained that the words could not be used, making retention of meaning difficult.

I think it is not very useful because we are memorise for test. Sometimes we forget it - we choose words that are not very common and we forget.

I don't like study vocabulary this style, because these word not useful. Nor useful for something you talk with someone. I don't use these words - it's just for study or reading vocabulary list.

Interestingly, although selection of the words to learn was the aspect of the vocabulary-learning process over which the informants had most control, none of these nine informants had made any attempt to alter their methods of selecting vocabulary in light of their dissatisfaction with the effects of their current behaviour. This failure to alter learning behaviour, even when it is clearly recognised that the system is not working for them, is perhaps the clearest indication that these learners are not taking responsibility for their own learning, or using the task to meet their own needs.

It could be argued that the learners have adapted well to the situation they are in, in that they are working hard, focusing on immediate goals, and picking up on cues from the teachers. However, this adaptation has only limired shortterm benefits and is certainly not what the teachers hoped for, and one of the practical goals of this study was to provide data for formative evaluation of the vocabulary component of the course so that there were long-term benefits.

\section{Case study of an effective vocabulary learner}

Abdi, a 23-year-old man from Somalia, was the informant who demonstrated the highest level of responsibility for his own learning. Interestingly, the results of his vocabulary test were also significantly higher ( 26 out of a possible 30 ) than any of the other informants. Abdi's approach to his vocabulary learning, and his beliefs about vocabulary learning, demonstrated an awareness both of his own needs and of what is involved in learning vocabulary.

\section{SELECTION OF WORDS}

Abdi's process for selecting items to learn was significantly different from the other informants, in that he almost always selected words that were at least partially known.
Mostly I just choose the words that I already know but I have to improve them or make them clear to me. Or I choose the one that are difficult to me - about how to use them in different situations.

Abdi also chose words to study from a wider range of sources than any of the orher informants, selecting words that he found particularly interesting or useful.

I learn words from talking to people, from TV and from radio. If that word is interesting I write on a small book. I always have a pen and notebook. Later I can put them in this list (vocabulary notebook).

\section{ASPECTS OFWORD KNOWLEDGE}

Abdi was the only informant to express concerns about levels of knowledge of particular items, demonstrating his awareness of the complexity of knowing a word. Abdi was familiar with the process of looking at different aspects of word knowledge, and placed value on being able to use words appropriately. He was the only informant interviewed who regularly attempted to find out more about the items to learn than was required by the test.

I try to find out some more sometimes - whether they are spoken, whecher they are written, whether informal. Maybe they are old or maybe they are fashion word. I want to know this, so sometimes I find in dictionary, and sometimes I can ask somebody.

Abdi was aware that items may have a variety of meanings, and could usually explain two or more meanings for each of the items tested. He was also aware of the impact that different meanings could have on his own language use.

If I only know one meaning, or one situation, maybe ir's not enough. Maybe I don't understand, or I make a mistake.

\section{LEARNING AND MEMORISING}

Abdi also used a greater range of strategies to learn the words selected each week than any other informant. In addition to a certain amount of rereading and memorising from the vocabulary notebook, Abdi made flash cards for each word on his list, and carried these cards with him to revise his vocabulary at every available opportunity: while walking, riding on the bus, or having lunch. Abdi made use of small amounts of time to revise his weekly vocabulary.

Abdi's other vocabulary learning strategy was to make a direct effort to use those words at every available opportunity, in a variety of contexts. He believed that saying the words aloud in a sentence helped him to remember them.

I rry to speak to the native person as much as I can every day. I talk to them and try to use new vocabulary ... if I use in different situations I can remember that word. I just talk every day. Sometimes even I talk to myself. 


\section{REYISION}

Like the other informants, Abdi did not make a habit of regularly reviewing all the vocabulary in his notebook, although he did revise any vocabulary that was marked incorrect in the weekly test. However, Abdi did make a consisten effort to use the vocabulary he learned each week in his writing and speaking, constantly reinforcing his understanding of the words and his ability to use them.

\section{SELF-EVALUATIONAND MONITORING}

Abdi was the only informant who was confident that he knew all the vocabulary he had learned in the program, and was able to use each of the words productively, often using more than one meaning of single items. He reported that he believed the vocabulary-learning program was working effectively for him, and was totally happy with his progress.

The test results presented in the next section confirm Abdi's beliefs relating to the effectiveness of his vocabulary learning.

\section{Vocabulary test results}

Results of the vocabulary interview tests conducted with each informant showed that generally they did not retain meaning or know how to use the items productively. Although most of the informants interviewed for this study believed they were completing the task in the manner that was required by the course and spent many hours studying vocabulary every week, their retention of the tested items and ability to use those items were minimal.

Tests were scored according to an adaptation of Wesche and Paribakht's (1996) Vocabulary Knowledge Scale (Table 2). Marks were given for meaning, and the ability to use the words with appropriate semantic collocations and grammatical accuracy. Table 3 gives the grades and categories on the revised word knowledge scale. Each of the ten words tested could gain a score from 0 to 3 .

\section{Table 2: Revised vocabulary knowledge scale}

Score Description of knowledgelability

Informant has no knowledge of word meaning or ability to use the item.

1 Informant is able to provide a close definition or appropriate collocations but is unable to use the word productively.

Informant an provide a clear definition of the item, and can use the item with either appropriate collocations or grammatical accuracy.

3 Informant can provide a clear definition of the item and can use the item productively with appropriate collocations and grammatical accuracy.
Table 3: Test results for the ten learners

\begin{tabular}{lccccc}
\hline Informant & $\mathbf{0}$ & $\mathbf{1}$ & $\mathbf{2}$ & $\mathbf{3}$ & $\begin{array}{l}\text { Total individual } \\
\text { score }\end{array}$ \\
\hline Masa & 6 & 0 & 3 & 1 & 9 \\
Debbie & 4 & 1 & 3 & 2 & 13 \\
Kate & 3 & 3 & 3 & 1 & 12 \\
Mohamed & 5 & 3 & 1 & 1 & 8 \\
Sun ae & 4 & 2 & 1 & 3 & 13 \\
Haruko & 3 & 3 & 2 & 2 & 13 \\
Natalie & 2 & 3 & 3 & 2 & 15 \\
Jack & 3 & 0 & 3 & 4 & 18 \\
Sandy & 7 & 1 & 1 & 1 & 6 \\
Abdi & 0 & 1 & 2 & 7 & 26 \\
Total & 37 & 17 & 22 & $\mathbf{2 4}$ & Maximum $=30$ \\
\hline
\end{tabular}

Test scores are given for each informant. The middle four columns show the number of words for which a score of $0,1,2$ or 3 was given, while each informant's total score out of a possible 30 marks is given in the far right column.

For example, Sandy did not know seven of the ten words tested and thus scored 0 , but she gave an approximate definition for one word, a reasonable definition and an appropriate semantic collocation for one, and she defined one word correctly and used it accurately in context with appropriate semantic collocations. These scores combined gave Sandy a total score of six $(1+2+3)$ out of a possible 30 marks. The bottom row of the table shows the total number of words in each scoring category.

These test scores indicate that, for the most part, the approach to vocabulary learning within the program taken by these students is failing to contribute fully to their long-term vocabulary knowledge and communicative ability, since they appear to have completely forgotten many of the words they studied and do not seem to be able to use many of the others communicatively.

As revealed through the interviews, the majority of learners interviewed for this study failed to adopt strategies in order to meet their own vocabulary learning needs. They often chose words that were of limited personal interest, and did not meet their immediate needs, and the methods they used to learn the vocabulary appear to have failed to really help their long-term retention of vocabulary, or their ability to use the words communicatively. It appears that these learners are not seeing a reasonable return for the many hours spent studying vocabulary for this part of the program. 


\section{Causes and solutions}

A crucial factor that should not be forgotten is that the informants all felt that vocabulary learning was an important part of language learning.

I think vocabulary is very important. When I listen something, vocabulary help me to understand what they say. If I miss out two or three vocabulary I couldn' understand all the meaning. I have to push harder to learn more vocabulary.

Vocabulary is very important for me. If I have no vocabulary, how can I write? How can I understand something?

Vocabulary is essential for my English study. I think my main problem is vocabulary.

The informants interviewed all wanted to learn vocabulary, and were therefore investing a considerable amount of their study time in developing vocabulary using the program described. The apparently ineffective vocabulary strategy used by these learners was not due to low motivation or laziness.

In looking at the causes and solutions we will continue to follow the syllabusdesign model, considering goals, selection of words and aspects of knowledge, learning and revision procedures, and self-evaluation and monitoring.

\section{GOALS}

It is apparent from the transcripts of the interviews that the commonsense goals of learning useful vocabulary for long-term retention leading to use were largely replaced by less effective short-term goals. This occurred at least party through learners' views of teacher expectations, the influence of the weekly tests, and insufficient awareness of what is involved in knowing a word. We will look at these in detail in the following sections.

\section{SELECTION OFWORDS AND ASPECTS OFWORD KNOWLEDGE}

The learners often showed a limited awareness of their own vocabulary knowledge and what is involved in knowing a word. The vocabulary test that they sat at the beginning of the course, Vocabulary Levels Test (Nation 1990), may possibly have been influential here as it is designed to give learners as much credit as possible for what they know. Thus, even if a word is only partly known, learners may be able to answer the item testing it correctly. This could give learners an inflated idea of their vocabulary size, leading them to feel confident about words that they still need to explore more deeply.

I know first two thousand and three thousand level. I think I have perfect score for that level.
So, instead of working a little more on the higher-frequency words, learners tended to focus on those that were completely unknown.

I am lucky, I know two thousand and three thousand level already. I have to find some difficult words.

Many learners also did not appreciate that knowing a word involves much more than being able to recognise its form and connect it to a meaning.

In most traditional classroom contexts, the teacher is seen as an authority figure, and learners are generally required to comply with teacher expectations in their learning behaviour. One of the recurring themes in the interview data was the belief that the words that were being studied were not of personal interest to the learners. Although, by selecting their own words to study, learners were theoretically being given the opportunity to shape the vocabulary development program to meet their own needs, in fact, learners' choice of words was constrained to the implicit or explicit expectations of the teacher or the course.

Many of the informants perceived a teacher expectation that the learners ought to choose academic vocabulary, although most of these learners were more interested in general everyday vocabulary for immediate use.

Sometimes I hear a word and I think it is useful. You can use for conversation in every day. But you have to write down in your vocabulary for test, and I think for teacher this word is too easy, so I just choose some it is difficult and put in my test book.

After this course we have a big test. To choose everyday words, teacher said O.K but we should get big words for big final test - we should choose these academic words we get more chance for that test.

It is important to consider here that many of these learners, including Kate and Haruko, have no intention of enrolling in English medium academic study within the next six months, and a focus on academic vocabulary is likely to be of limited value to these learners at this time.

If a learner feels obliged to select a particular type of word, this not only limits that learner's ability to personalise the task to his or her own needs, but it is likely to decrease the feeling of ownership for the task. In effect, the task becomes something that is done to meet teacher expectations or course requirements, rather than to contribute to personal learning.

Interestingly, Abdi, the most effective of the informants, was the only learner who had been required to choose his own vocabulary to learn in his own country. He was also familiar with the process of learning collocations and grammatical information, emphasising the importance of depth of knowledge. 
The learners in this study were clearly willing workers. They spent a lot of time on their learning and were conscientious in completing tasks and preparing for tests. They did not always show the same willingness, however, in adapting the learning to their own needs. There is a big difference between working hard on tasks the teacher has set, and shaping the tasks to your own ends. More time may need to be spent helping learners to decide why they are learning vocabulary and what kind of vocabulary they need to learn. This decision-making could involve the teacher working with individuals in personal consultations or small groups discussing a range of possible goals and working out the appropriate vocabulary to reach these goals. It could involve the teacher modelling a discussion with one learner and then getting the learners to discuss their goals in small groups. Individual learners could then report to the rest of the class on their decisions.

\section{LEARNING AND MONITORING}

Most of the informants used a very limited range of strategies for vocabulary learning, and many of these reflected their previous learning experience.

I think course is 85 per cent learning by myself. Teacher not always teach abou English in here. This is different from Hong Kong. I suggest teacher can use three hours concentrated teach vocabulary - just use simple English to explain some word meanings.

Natalie

The most common strategies were rote learning and copying, and this may relate to the amount of strategy training that the learners received. During the course, the learners were introduced to strategies like guessing from context, using word cards, using mnemonic techniques like the key-word technique and word parts, and using dictionaries. But this is not sufficient for effective strategy use. Learners need to know not only about strategies and understand what they involve, but they need to become very comfortable with their use. Until they reach a satisfactory level of comfort with a strategy, it is unlikely that they will truly experience its effectiveness or find it as easy to use as their default strategy. Reaching this level of comfort with a strategy involves a considerable investment of time and effort. At a rough guess, learners may need to practise the key-word technique at least twenty times over several weeks before they find it easy to use. This may involve a total time investment of around three or four hours. Learning to guess from context and to use a dictionary effectively will each take even more time. Teachers need to plan a mini-syllabus for the development of each of the important strategies and monitor their development.

Learners need to reflect on and question their own learning behaviour. This can be done by getting learners to describe to others the way they approach their learning. Perhaps the use of a short list of points to cover, such as the selection of words, aspects of word knowledge, learning and memorising, and revising, may help them to get started. Talking to others and listening to others talk about their approaches to learning can provide an awareness of more options, and these can be a beginning point for change. Direct teaching about different types of vocabulary and their usefulness, what is involved in knowing a word, strategies for vocabulary learning, and the need to consider revision can help increase awareness. Learners can also keep a written record of their own learning including their reflections on what worked well and what did not.

A few informants reported attempts to use new vocabulary creatively and communicatively in their personal learning. Two informants, Haruko and Sun ae, also attempted to make connections between new words and prior knowledge when learning vocabulary for personal use.

I think I can find some effective way. If I can't memorise, I try to connect this word to other thing. I try to find another word I already know, and I can connect that meaning.

Some words it's easy to remember. I try, I can fix that with something I know.

Bur sometimes I can't fix in my mind, so that one just fall out from my head. Haruko

These strategies however were not often carried over from learning for personal use to learning within the classroom context.

\section{SELF-EVALUATIONAND MONITORING}

An important aspect of being independent in learning is the strategy of reflecting on behaviour and progress and deciding on adaptations and adjustments on the basis of this reflection.

Constant references to the weekly test throughout the majority of the interview transcripts also reveal they had a limited ability to relate the learning task to their own needs.

I think it is not good way. We are studying for test. Before the test we study hard, very hard. After the test we forget everything.

Debbie

Although the weekly test does not contribute to any final grade and is designed primarily as a tool for learners to monitor their own progress, most of the learners expressed a desire to achieve high grades in the test, and many comments were made relating learning specifically to the test. One informant, Sun ae, was fully aware of the influence that the weekly tests had on her approach to learning vocabulary. 
I think I am too sensitive to test. I use that vocabulary notebook and I scudy, just memorise for the test, this is not a good way ... in Korea the rest marks are very important thing. Somerimes we don't need critic thinking, just memorise for good marks.

Sun ae

Teachers also need to consider the effect of the tests they use and the suggestions they give to learners. There may seem to be flexibility in a course, but the learners may feel that there is a hidden agenda that they must follow, and discussion between teachers and learners is one way of making any such expectations explicit. This study has shown that it is very important for teachers to spend time looking closely at what learners do, and it is even more important for learners to consider what they do and whether it is truly helping them meet the goals that they value. Teachers can play an important role in helping learning, but ultimately it is the learners themselves who do or do not learn. Teachers may unwittingly deflect learners from useful goals through the assessment tasks they use and through the comments that they make. Under these circumstances, continuing discussion of the goals of the program and ways of achieving these goals is essential so that teachers and learners can have common purposes which benefit both teaching and learning.

\section{REFERENCES}

Dunmore, D 1989. 'Using contextual clues to infer word meaning: An evaluation of current exercise types'. Reading in a Foreign Language, 6, 1: 337-47

Gu Yongqi and R K Johnson 1996. 'Vocabulary learning strategies and language learning outcomes'. Langtadge Learning, 46, 4: 643-79

Lawson, $\mathrm{MJ}$ and $\mathrm{D}$ Hodben 1996. 'The vocabulary-learning strategies of foreign-language students'. Language Learning, 46, 1: 101-35

Murdoch, G S 1989. 'A pragmatic basis for course design'. English Teaching Forum, 27, 1: $15-18$

Nation, IS P 1990. Teaching and learning vocabulary. Massachusetts: Heinle and Heinle

Nation, I S P 2000. 'Designing and improving a language course'. English Teaching Forum, 38, 4: 2-11

Nation, I S P 2001. Learning vocabulary in another language. Cambridge: Cambridge University Press

Richards, J C 1976. 'The role of vocabulary teaching'. TESOL Quarterly, 10, 1: 77-89

Schmitt, N 1997. Vocabulary learning strategies. In N Schmitr and M McCarthy' (eds). Vocabulary: Description, acquisition and pedagogy. Cambridge: Cambridge Universicy Press

Schmitt, N 2000. Vocabulary in langzage teaching. Cambridge: Cambridge University Press

Schmitt, N and D Schmitt 1995. "Vocabulary notebooks: Theoretical underpinnings and practical suggestions'. ELT Journal, 49, 2: 133-43
Sokmen, A 1997. Current trends in teaching second language vocabulary. In N Schmitt and M McCarthy (eds). Vocabulary: Description, acquisition and pedagogy. Cambridge: Cambridge University Press

Wesche, M and T S Paribakht 1996. Assessing second language vocabulary knowledge: Depth versus breadth'. Canadian Modern Language Review, 53, 1: 13-40

34 Prospect Vol. 17, No. 1 April 2002 
